\title{
Study of the Activation and Oxygenation of Multifidus and Gluteus Medius Muscles During Stretching of the Lower Limb Posterior Chain: Comparison Between Two Different Executions Techniques
}

\author{
L. Calanni ${ }^{1}$, F. Combi ${ }^{2}$, L. Rampi ${ }^{1}$, M. Negro ${ }^{1}$, L. Spairani ${ }^{2}$, G. D'Antona ${ }^{1,3}$ \\ 1 CRIAMS-Sport Medicine Centre, University of Pavia, Voghera, Italy \\ 2 Studio Spairani, Torre d'Isola, Pavia, Italy \\ 3 Department of Public Health Experimental and Forensic Medicine, University of Pavia, Pavia, Italy
}

\section{CORRESPONDING AUTHOR:}

\section{Giuseppe D'Antona}

Department of Public Health

Experimental and Forensic Medicine and Sport Medicine Centre Voghera 13 Foscolo Road

Voghera, Italy, 27058

E-mail: gdantona@unipv.it

DOI:

10.32098/mltj.03.2020.10

LEVEL OF EVIDENCE: 3B

\section{ABBREVIATIONS}

HHB: Deoxygenated Hemoglobin sEMG: surface Electromyography NIRS: Near Infrared Spectroscopy TOI: Tissue Oxygen Index

$\mathrm{HBO}_{2}$ : Oxygenated Hemoglobin

THB: Total Hemoglobin

\begin{abstract}
SUMMARY
Background. Ischiocrural (IC) stretching procedures may result in different involvement of the posterior kinetic chain and of the lumbar spine.

Objective. The aim of the study was to evaluate homolateral muscle activation and hemodynamic changes in the Multifidus (MM) and Gluteus medius (GM) muscles in healthy subjects during monolateral IC stretching by using two different execution techniques: technique A (TA: forward bending of the torso, hands in Open Kinetic Chain (OKC), leg stretched) and technique B (TB: forward bending of the torso, leg stretched with knee joint angle of $20^{\circ}$, hands in Closed Kinetic Chain (CKC).

Methods. A total of 12 recreationally active males (35-24 \pm 4.2 years) and 14 recreationally active females (26-22 \pm 2.3 years) volunteered to participate in the study and randomly performed TA and TB stretching of $20 \mathrm{~s}$ in two subsequent sessions one week apart. During execution, hemodynamic parameters obtained with near infrared spectroscopy (NIRS), namely total hemoglobin ( $\mathrm{tHb}$ ) and tissue oxygen index (TOI\%), as indicators of blood flow and oxygen extraction respectively, were detected from homolateral MM, and myoelectric parameters obtained with surface bipolar electromyography (sEMG), namely root mean square (RMS) as indicator of muscle activation, were detected from homolateral GM and MM. Percentage of change $(\Delta \%)$ was calculated from the beginning and the end of the $20 \mathrm{~s}$ recording divided into $5 \mathrm{~s}$ epochs for all the parameters measured.

Results. All along the $20 \mathrm{~s}$ procedure, compared to TB, TA stretching produced higher muscle activation both in MM and GM muscles $(\mathrm{p}<0.001)$, and lower $\mathrm{tHB} \%$ change combined with higher \% oxygen extraction in $\mathrm{MM}(\mathrm{p}<0.05)$.

Conclusions. Stretching of the posterior kinetic chain of the lower limbs with $20^{\circ}$ bent homolateral knee and hands in CKC prevents MM and GM overload and may represent a useful technique, alternative to classical stretching, to prevent low back pain.
\end{abstract}

KEY WORDS

Hamstrings; low back pain; near infrared spectroscopy; electromyography; stretching.

\section{BACKGROUND}

Elongation (stretching), involves different types of tissues: connective tissue, contractile proteins, muscle bands, tendons, aponeuroses, ligaments (1) and complex neurological systems regulating afferences and proprioceptive responses (2). Its efficacy, for prevention and re-ed- ucational purposes, has been extensively documented in literature (3-5). Among the various modalities of stretching, the static technique is the most frequently used and involves the slow elongation of a muscle or a muscular chain maintained to the maximum bearable $(6,7)$ for a time varying from few seconds up to one minute (8). 
The posterior kinetic chain (PKC) elasticity of the lower limbs, involving ischiocrural (IC) and triceps sural (TS) districts, is essential for the correct functionality of the lumbar district (LD) (9). There is evidence in that the IC rigidity, decreasing the physiological lumbar lordosis, may cause DL overload thus promoting low back pain $(1,10)$. Based on these observations, the correct elongation of IC is considered a pivotal strategy to prevent and/or treat this clinically relevant condition (11).

The classic, widely adopted, IC stretching procedure requires that the ipsilateral lower limb is fully extended. In this position, IC muscles may prevent retroversion of the pelvis thus avoiding its rotation forward on the femoral heads during flexion of the trunk and subsequently overloading the LD structures and muscles.

In the present study we analyzed the level of Gluteus medius (GM) and Multifidus muscle (MM) activation, by means of surface electromyography (sEMG), and the hemodynamic parameters (total hemoglobin and tissue oxygen index as indicators of blood flow and oxygen extraction respectively), by means of near infrared spectroscopy (NIRS), of the GM and MM during IC stretching executed with TA (hands in OKC and ipsilateral lower limb stretched), and with TB (hands in CKC and ipsilateral lower limb with $20^{\circ}$ knee joint angle) techniques in healthy young subjects.

Results obtained demonstrated that TB technique determines higher IC elongation while reducing overload on LD.

\section{MATERIALS AND METHODS}

\section{Subjects}

26 recreationally healthy young subjects (age 28.5 \pm 6.5 years; body weight $66 \pm 20 \mathrm{~kg}$, height $171 \pm 18 \mathrm{~cm}$ ), 12 males (age $30 \pm 5$ years; body weight $73 \pm 8 \mathrm{~kg}$, height $176 \pm 4 \mathrm{~cm}$ ) and 14 females (age $24 \pm 2$ years; body weight $62 \pm 9 \mathrm{~kg}$, height $167 \pm 7 \mathrm{~cm}$ ). The subjects were fully informed of the objectives, risks and discomfort associated with the experimental research and provided their informed consent written to participate in this study, before completing a questionnaire to assess their status of health. Exclusion criteria were: joint prostheses, prostheses, artificial implants (hip, knee, ankle and shoulder) or spinal cord plaques, lumbar or sciatica pain in the last three months, arthrodesis of the tibio-tarsica joint, tarsus, metatarsal and phalanges of the feet, paralytic arthritis, recent (less than three months) tear or lesion of the ischiocrural and/or sural triceps muscles, femorotibial arthrosis; recent surgical procedures, and BMI $>30 \mathrm{~kg} / \mathrm{m}^{2}$. The study was conducted at CRIAMSSport Medicine Centre Voghera, University of Pavia, Italy and was approved by the institutional local Review Board. The present study meets the ethical standards of the journal (12).

\section{Experimental procedure}

All subjects performed static IC unilateral stretching of the dominant leg using two techniques (technique A, TA and technique $\mathrm{B}, \mathrm{TB}$, see below) in two separate sessions 1 week apart, in a randomized fashion. During the same session sEMG and NIRS measurements were made in two subsequent randomized stretching procedures separated by $10 \mathrm{~min}$ interval. Experimental procedures were conducted between 9 and $11 \mathrm{a} . \mathrm{m}$. at optimal temperature $\left(22^{\circ} \mathrm{C}\right)$ and humidity $(50 \%)$ environmental conditions.

\section{Technique A (TA)}

The subject, sitting on a medical table, performed unilateral static stretching for the hamstrings of the dominant leg, maintained in neutral rotation with the ankle dorsiflexed. The hip was passively flexed, with head extended, to the maximum angle which could be tolerated without stretch pain, with the knee fully extended trying to reach the feet with the hands in open kinetic chain (OKC) and this position was maintained for $20 \mathrm{~s}$. For each subject the final angle was measured after stretching. The final angle was defined as that formed by the tibia and horizontal plane when the knee was passively extended from hip and knee angles at $90^{\circ}$ flexion to the maximum extension angle which could be tolerated without stretch pain. During procedure the non-dominant leg was maintained dangling from the edge of the cot in neutral position.

\section{Technique $B(T B)$}

The subject sitting on a medical table, performed unilateral static stretching for the hamstrings of the dominant leg, maintained in neutral rotation with the ankle dorsiflexed. The hip was passively flexed, with head extended to the maximum angle, which could be tolerated without stretch pain. During elongation the knee joint maintained at $20^{\circ}$ flexion; during procedure the hands were resting on the surface of the cot in closed kinetic chain (CKC). In each subject position was maintained for $20 \mathrm{~s}$ at the bending angle previously measured during TA (or vice versa).

\section{sEMG measurement}

Analog sEMG signals were captured by applying bipolar disposable circular surface electrodes $(\mathrm{Ag} / \mathrm{AgCl}$, OT Bioelettronica Torino, $1 \mathrm{~cm}$ diameter) with an interdistance of $2 \mathrm{~cm}$. Surface electrodes were placed on the skin of the dominant leg and ipsilateral low back, parallel to the muscle 
fibers, to record muscle activity of the gluteus medius (GM) and lumbar multifidus (MM) muscles. Before positioning skin, shaved if necessary, was gently abraded and cleaned with $75 \%$ alcohol to reduce electrical impedance. Electrode handling was in accordance to SENIAM guidelines (13). In GM the electrode was placed in mid-point of a line along the length of the iliac crest (IC), and placed at 34\% of the distance from the greater trochanter of the femur (14). In MM the electrode was positioned $1 \mathrm{~cm}$ medial from line between posterior superior iliac spine and 1st palpable spinous process, lower electrode border at L4 level(15). To ensure reliability of electrode positioning every investigation was carried out by the same examiners (LC and FC). 4-resolution channel data acquisition system (Quattro Ot-Bioelettronica, Torino), consisting of a signal conditioner with a band-pass filter of $10-500 \mathrm{~Hz}$ and amplifier gain of 2000, input impedance $1200 \mathrm{GW}$, noise level $<1 \mathrm{mV}$, was used to obtain biological signals. All data were processed and exported for analysis by a specific software (Quattro software, OT Bioelettronica, Torino). Captured sEMG activity was converted by an A/D board with a 12-bit resolution input range, sampling frequency of $2024 \mathrm{~Hz}$. Average rectified value (ARV) was computed over $5 \mathrm{~s}$ epochs of the recorded raw EMG signal by full-wave rectification to represent the muscle activity.

\section{NIRS}

Measurements of deoxyhaemoglobin [HHb], oxyhaemoglobin [HbO2], and total haemoglobin $[\mathrm{HbT}]$ concentrations and the muscle \% hemoglobin oxygen saturation (tissue oxygen index, TOI \% \%) was also calculated as ( $\Delta$ $\left.\mathrm{HbO}_{2} /\left(\Delta \mathrm{HHb}+\Delta \mathrm{HbO}_{2}\right)\right) \times 100$ were obtained with a continuous-wave tissue oximeter (NIMO, Nirox srl, Brescia, Italy).

Briefly, based on the assumption that at $975 \mathrm{~nm}$ the absorption coefficient is dominant over other chromophores (i.e. $\mathrm{HbO}_{2}$ and $\mathrm{HHb}$ ) and that water absorption and that the tissue scattering properties vary linearly with wavelength, the scattering spectrum is calculated at this wavelength thus allowing the estimation of absorption coefficient at 685 and $830 \mathrm{~nm}$ thus allowing measurements of absolute $\mathrm{HbO}_{2}$ and $\mathrm{HHb}$ tissue concentrations. In each subject, data obtained by continuous recording were subsequently sub grouped in $5 \mathrm{~s}$ epoch intervals, averaged and plotted. At each time point, absolute values obtained from each subject were subsequently averaged and differences of the means obtained in TA and TB were statistically analyzed. To account for the possible influence of the fat layer (previously measured by ultrasound) on NIRS measurements, a real-time correction was applied using an algorithm includ- ed in the software supplied with the spectrometer (Nimo Data Analysis version 2.0). For NIRS tests, the probe was placed in the same position of the sEMG electrodes only in $\mathrm{MM}$, whereas GM was discarded from the analysis due its physiological curve that avoided correct positioning of the probe during stretching. To prevent artifacts from external lights the NIRS probe was firmly secured with a small velcro strap and covered with dark coating. The probe edges were marked on the skin in order to avoid any downward sliding during movements.

\section{Statistical analysis}

Linear regression was applied to the data to calculate the initial value and rate of change of ARV. Normalized rate of change for each variable was calculated as the percentage ratio between rate of change and initial value. Paired and unpaired t-test was used to compare significant differences between recorded parameters in TA vs TB and between genders respectively. The data are reported as mean \pm standard deviation (SD). Statistical analysis was completed using Graphpad 5 (San Diego, California) and the significance level was set at $\mathrm{p} \leq 0.05$.

\section{RESULTS}

Considering that no significant differences were found between males and females at every time point and for every parameter measured, data were pooled for subsequent statistical analysis.

Average percentage changes of RMS recorded at $5 \mathrm{~s}$ intervals between initial and final stretching are reported in Table I for MM and Table II for GM. Compared to TB, TA stretching produced significant higher muscle activation both in MM and GM muscles at every time point along the $20 \mathrm{~s}$ stretching procedure. As regards the hemodynamic parameters recorded in homolateral MM (Table III), a slightly change in blood volume $(\Delta \% \mathrm{tHb})$ was observed in $\mathrm{TA}$ and $\mathrm{TB}$ at each time intervals without significant difference between procedures, whereas a higher oxygen extraction $(\Delta \% \mathrm{TOI})$ was observed in TA compared to TB at 10,15 and 20 time intervals (Table III), thus suggesting that an improved oxygen extraction was maintained to sustain the higher muscle activation during stretching.

\section{DISCUSSION AND CONCLUSION}

The objective of this study was to compare two different stretching techniques, TA and TB, of the IC muscles to determine which one least overload LD muscles. To this aim, by combining sEMG and NIRS techniques to study GM and MM activation and oxygenation during $20 \mathrm{~s}$ IC 
Table I. Root Mean Square (RMS) percentage of change from baseline in homolateral Multifidus muscle at $5 \mathrm{~s}$ intervals during TA and TB stretching and percentage difference between TA and TB at each time point.

\begin{tabular}{|c|c|c|c|c|c|c|c|c|}
\hline \multicolumn{3}{|c|}{$\Delta \%$ RMS di Multifidus (TA) } & \multicolumn{3}{|c|}{$\Delta \%$ RMS di Multifidus (TB) } & \multicolumn{3}{|c|}{$\begin{array}{l}\Delta \% \text { RMS Multifidus } \\
\text { TA vs TB }\end{array}$} \\
\hline Time $(\mathrm{s})$ & mean & $\mathrm{SD}$ & Time $(\mathrm{s})$ & mean & $\mathrm{SD}$ & Time (s) & mean & $\mathrm{SD}$ \\
\hline 5 & 9.0 & \pm 25.22 & 5 & 5.0 & \pm 18.90 & 5 & 44.5 & \pm 40.37 \\
\hline 10 & 12.8 & \pm 34.05 & 10 & $-4.0 *$ & \pm 18.31 & 10 & 131.1 & \pm 41.43 \\
\hline 20 & 17.4 & \pm 30.69 & 20 & $-13.0 * *$ & \pm 31.52 & 20 & 174.4 & \pm 55.74 \\
\hline
\end{tabular}

* significantly different from TA ( $\mathrm{p}<0.05)$. ** significantly different from TA ( $\mathrm{p}<0.001)$. s, seconds; SD, Standard Deviation.

Table II. Root Mean Square (RMS) percentage of change from baseline in homolateral Gluteus medius at $5 \mathrm{~s}$ intervals during TA and TB stretching and percentage difference between TA and TB at each time point.

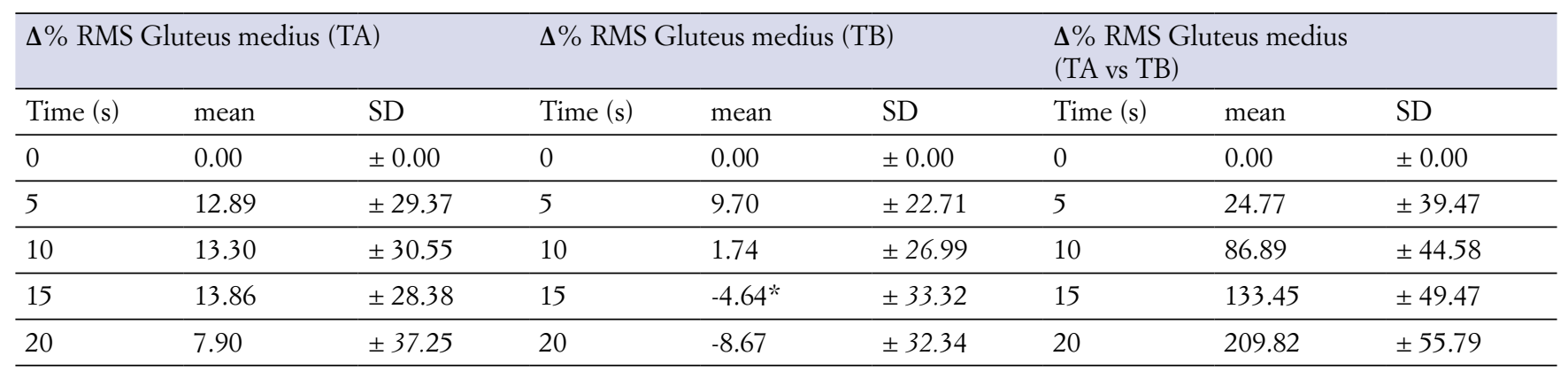

* significantly different from TA $(\mathrm{p}<0.05)$. s, seconds; SD, Standard Deviation.

Table III. Total $\mathrm{Hb}$ (Hbtot) and TOI percentage of change from baseline in homolateral Multifidus muscle at $5 \mathrm{~s}$ intervals during TA and TB stretching and percentage difference between TA and TB at each time point.

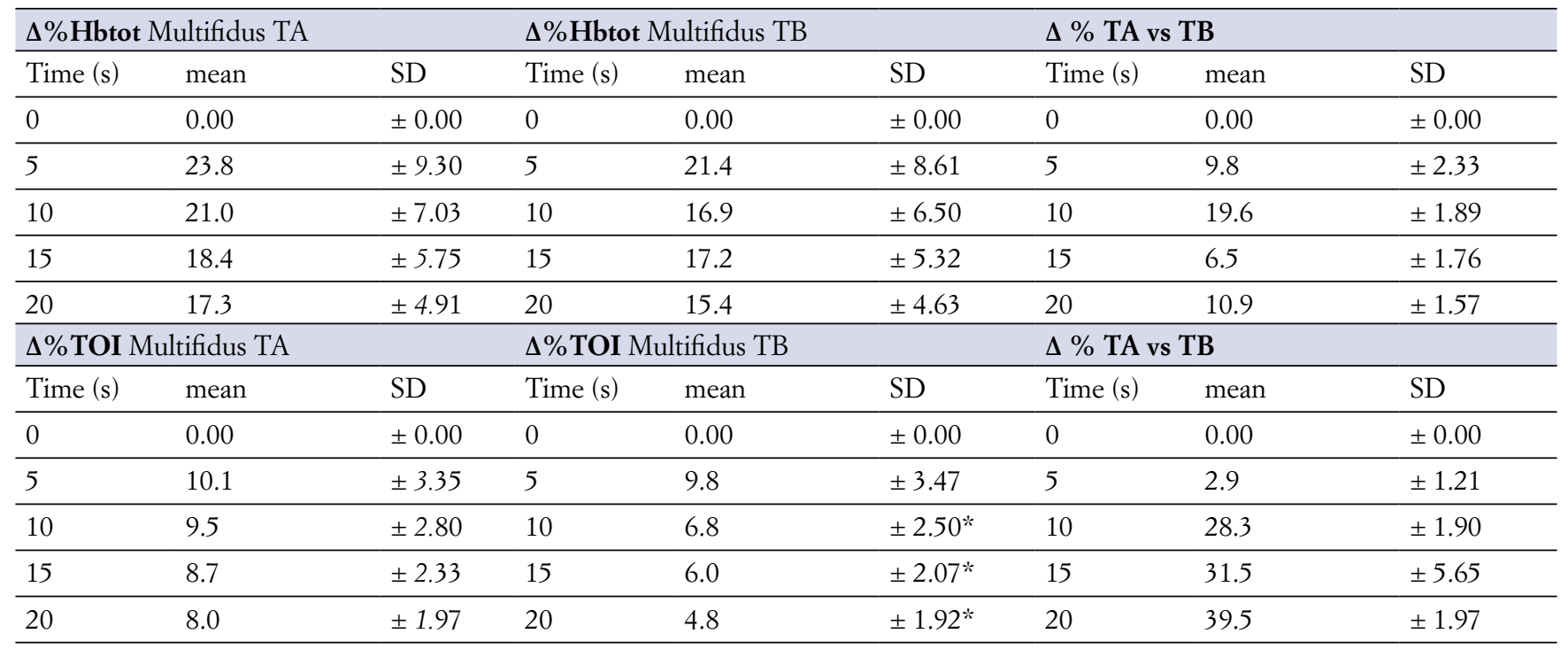

* significantly different from TA $(\mathrm{p}<0.05)$. s, seconds; SD, Standard Deviation. 
stretching, the main findings were: 1) a higher muscles activation in TA compared to TB at each $5 \mathrm{~s}$ epochs of the stretching period; 2 ) no difference in the percentage change of total hemoglobin and a higher oxygen uptake detected in MM during TA compared to TB; 3 ) no difference in muscle activation and oxygenation in males compared to females in both stretching procedures.

Shortening or tightness of the hamstrings affects postural alignment and results in possible musculoskeletal pain. The kinematics of the lumbar district and of the Coxo-Femoral joint (CF), also called lumbar-pelvic rhythm, was studied during the flexion of the trunk in some daily activities living (ADL), in people with or without low back pain $(16,17)$. In the bending of the trunk, upon reaching the maximum opening of the lumbar veneer joints $\left(\approx 60^{\circ}\right)(18)$, the elasticity of the IC induces a coordinated anterior rotation of the pelvis on the femoral heads (10), thus allowing an increase of the trunk bending without further stress to the DL structures $(10,19)$. In contrast, excessive rigidity of the IC muscles, due to their proximal insertion on the ischial tuberosity, by retaining the pelvis, restricts the muscles rotation forward on the femoral heads, thus causing excessive stress in lengthening of the connective structures of the LD. This condition is associated with higher probability of fatigue of the paravertebral muscles and subsequent onset of low back pain (20). As previously demonstrated, the use of various postures during the IC stretching procedure for may result in different involvement of the PKC and of the lumbar spine $(21,22)$. Our results, for the first time, demonstrate that stretching of the posterior kinetic chain of the lower limbs with $20^{\circ}$ bent homolateral knee and hands in CKC prevents MM and GM overload. In fact, a lower muscles activation and contemporary lower oxygen uptake along the $20 \mathrm{~s}$ stretching period was observed in TB stretching. The observed differences in muscles activation

\section{REFERENCES}

1. Wiemann K, Hahn K. Influence of strength, stretching and circulatory exercises on flexibility parameter of the human hamstrings. Int J Sports Med 1997; 18: 340-46.

2. Sale DG, Quinlan J, Marsh E, McComas, AJ, Belanger AY. Influence of joint position on ankle plantarflexion in humans. $J$ Appl Physiol 1982; 52: 1636-42.

3. Shellock FG, Prentice WE. Warming up and stretching for improved physical performance and prevention of sports related injuries. Sport Medicine 1985; 2: 267-78.

4. Porter JL, Wilkinson A. Lumbar hip flexion motion. A comparative study between asymptomatic and chronic low back pain in 18 to 36 year old. Med Spine 1997; 22: 1508-13.

5. Witvrouw E, Daneels L, Asselman P, D'Have T, Cambier D. Muscle flexibility as risk factor for developing muscle injuries and oxygenation in TA compared to TB may be due the unfavorable lever arm with greater stress in the pivotal area of the movement, LD and the sacroiliac joint, to which it may contribute the position of the upper limbs stretched out forward without any support in an open kinetic chain. Importantly, an increased GM activation has been found both in classic IC static and in the dynamic stretching and its possible role as critical factor for lumbar pain has been hypothesized in healthy subjects, following the long lasting maintenance of the erect station (23). Therefore, TB stretching may represent a useful technique, alternative to classical static stretching, to prevent low back pain.

\section{LIMITATIONS OF THE STUDY}

This study has limitations that need to be addressed. First, no data are presented regarding GM and MM sEMG adaptation following repeated stretching procedures. Further, IC muscles activation measurement during stretching procedures was not performed. This lack hampers the possibility to unravel the contribution of concurrent involuntary hamstring muscle activity contraction in limiting the hip range of motion in the tested stretching procedures and its role in stretching training (24). Further, changes in blood flow through the muscle tissue has not been measured directly but through the blood volume $\left(\mathrm{HBO}_{2}+\mathrm{HHb}\right)$. Based on the present limitations, future studies should expand the presented data, to confirm whether beneficial lesser LD overload due to TB compared with TA is verifiable following stretch training as well as following a single stretching session.

\section{CONFLICT OF INTERESTS}

The authors declare no conflict of interests.

in male professional soccer players. A prospective study. Am J Sports Med 2003; 31: 41-6.

6. Behm DG, Bambury A, Cahill F, Power K. Effect of acute static stretching on force, balance, reaction time, and movement time. Med Sci Sports 2004; 36: 1397-1402.

7. Cronin J, Nash M, Whatman C. The acute effects of hamstring stretching and vibration on dynamic knee joint range of motion and jump performance. Phys Ther Sport 2008; 9: 89-96.

8. Ebben WP, Carroll RM, Simenz CJ. Strength and conditioning practices of National Hockey League strength and conditioning coaches. J Strength Cond Res 2004; 18: 889-97.

9. Nourbakhsh MR, Arab AM. Relationship between mechanical factors and incidence of Low back pain. J orthop Sports Phys Ther 2002; 32, 447-60. 
10. Esola MA, McClure PV, Fitzgerald GK, Siegler S. Analysis of lumbar spine and hip motion during forward bending in subjects with and without a history of low back pain. Spine 1996; 21, 71-8.

11. Worrell TW, Perrin DH, Gansneder BM, Gieck JH. Comparison of isokinetic strength and flexibility measures between hamstring injured and noninjured athletes. J Orthop Sports Phys Ther 1991; 13, 118-25.

12. Padulo J, Oliva F, Frizziero A, Maffulli N. Muscle, Ligaments and Tendons Journal-Basic principles and recommendations in clinical and field science research: 2016 update. MLTJ 2016; 6: 1-5.

13. Hermens HJ, Freriks B, Disselhorst-Klug C, Rau G. Development of recommendations for SEMG sensors and sensor placement procedures. J Electromyogr Kinesiol 2000; 10, 361-374.

14. Rainoldi A, Melchiorri G, Caruso I. A method for positioning electrodes during surface EMG recordings in lower limb muscles. J Neurosci Methods 2004; 134, 37-43.

15. Huebner A, Faenger B, Schenk P, Scholle HC, Anders C. Alteration of Surface EMG amplitude levels of five major trunk muscles by defined electrode location displacement. J Electromyogr Kinesiol 2015; 25: 214-23.

16. Li Y, McClure PW, Pratt N. The effect of hamstring muscle stretching on standing posture and on lumbar and hip motion during forward bending. Phys Ther 1996; 76, 836-45.

17. Shum GL, Crosbie J, Lee RY. Effect of low back pain on the kinematics and joint coordination of the lumbar spine and hip during sit to stand and stand to sit. Spine 2005; 30, 1998-2004.
18. Kapandji AI. Physiology of the Joints. London; Churchill Livingstone 6th Edition 2010.

19. Perret C, Poiraudeau S, Fermanian J, Revel M. Pelvic mobility when bending forward in standing position: validity and reliability of two motion analysis devices. Phys Med Rehabil 2001; 82: 221-6.

20. Kendall FP, Kendall McCreary E, Provance PG, McIntyre Rodgers M., Romani WA. Muscles: Testing and Testing and Function with Posture and Pain. Baltimore and Philadelphia; Lippincott Williams \& Wilkins 5th Edition 2005.

21. Herda TJ, Cramer JT, Ryan ED, McHugh MP, Stout JR. Acute effects of static versus dynamic stretching on isometric peak torque, electromyography, and mechanomyography of the biceps femoris muscle. Strenght Cond Res 2008; 22: 809-17.

22. Boyce D, Brosky JA. Determining the minimal number of cyclic passive stretch repetitions recommended for an acute increase in an indirect measure of hamstring length. Physioter Theory Pract 2008; 24, 113-20.

23. Nelson-Wong E, Gregory DE, Winter DA, Callaghan JP. Gluteus medius muscle activation patterns as a predictor of low back pain during standing. Clin Biomech (Bristol, Avon) 2008; 23: 545-53.

24. Foo Y, Héroux ME, Chia L, Diong J. Involuntary hamstring muscle activity reduces passive hip range of motion during the straight leg raise test: a stimulation study in healthy people. BMC Musculoskelet Disord 2019; 20, 13. 